\section{Commentary: Can we truly get Staphylococcus aureus infectivity of biologic heart valve conduits to slip away?}

\author{
Ibrahim Abdullah, MD, and Zohair Al-Halees, MD
}

In this issue of the Journal, Ditkowski and colleagues, ${ }^{1}$ through an elaborate series of in vitro experiments, present compelling evidence for the prominent role of platelets and fibrinogen in the development of Staphylococcus aureus infective endocarditis (IE) of biologic heart valve conduits. ${ }^{1}$ Specifically, they focus on the complex interaction of Staphylococcus clumping factor A (ClfA), fibrinogen, platelet $\alpha_{\mathrm{IIb}} \beta_{3}$ receptors, and platelet adenosine diphosphate receptors as modulators of bacterial adhesion on various graft tissues. Their early experiments demonstrate the relatively higher binding of fibrinogen and platelets to bovine pericardial patch and bovine jugular vein (BJV) graft wall relative to cryopreserved homograft $(\mathrm{CH})$ tissue. This then has allowed them to develop experiments focused on the higher affinity bovine pericardial patch and BJV wall grafts as they assess $S$ aureus infectivity. Perhaps the most fascinating series of experiments depicts the effects of platelet inhibitors on bacterial adhesion. A remarkable $52 \%$ reduction in bacterial adhesion to BJV wall is demonstrated when eptifibatide, a platelet $\alpha_{\mathrm{IIb}} \beta_{3}$ receptor pathway inhibitor, is used. The effect is even greater, at $71 \%$ bacterial inhibition, when dual antiplatelet therapy with aspirin and ticagrelor, an adenosine diphosphate receptor inhibitor, is used. Given this convincing in vitro analysis, should dual antiplatelet therapy be applied universally for right ventricular outflow tract reconstruction with bioprosthetic valve conduits?

Ditkowski and colleagues ${ }^{1}$ rightly point out that IE can be a lethal disease, particularly when it involves bioprosthetic

\footnotetext{
From the Department of Pediatric Cardiac Surgery, King Faisal Specialist Hospital \& Research Center, Riyadh, Saudi Arabia.

Disclosures: Authors have nothing to disclose with regard to commercial support.

Received for publication Dec 2, 2019; accepted for publication Dec 2, 2019; available ahead of print Dec 9, 2019.

Address for reprints: Ibrahim Abdullah, MD, Department of Pediatric Cardiac Surgery, King Faisal Specialist Hospital \& Research Center, Riyadh, Saudi Arabia (E-mail: iabdullah1234@gmail.com).

J Thorac Cardiovasc Surg 2021;161:e475-6

$0022-5223 / \$ 36.00$

Copyright (c) 2019 by The American Association for Thoracic Surgery

https://doi.org/10.1016/j.jtcvs.2019.12.002
}

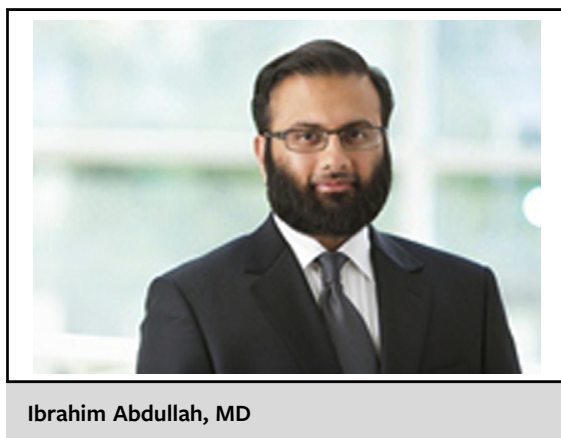

CENTRAL MESSAGE

Experimental evidence supports aggressive antiplatelet therapy in minimizing Staphylococcus aureus infectivity of biologic heart valve conduits.

cardiac valves and valve conduits. With an increasing number of bioprosthetic pulmonary valve implantations, this is now concerning not only for surgeons but also for interventional cardiologists. The burden of managing endocarditis is tremendous, consuming multiple hospital resources. There is thus no doubt that any additional safe intervention that would limit this complication is welcome.

In the experience at King Faisal Specialist Hospital and Research Center, we retrospectively analyzed 88 patients who had undergone the Ross operation who later underwent a transcatheter versus surgical pulmonary valve replacement for a failed pulmonary homograft. ${ }^{2}$ We found a significantly greater incidence of IE in transcatheter stented BJV pulmonary valves than in surgical pulmonary valves. Given the overall higher incidence of IE with BJV conduits, the surgical practice at King Faisal Specialist Hospital and Research Center has since tended to avoid BJV conduits in favor of $\mathrm{CH}$ conduits when available-much in line with the experimental findings of Ditkowski and colleagues. ${ }^{1}$ Another clinical study from Belgium analyzing 738 right ventricular outflow tract conduits in 25 years confirmed the higher incidence of IE in stented and nonstented BJV conduits relative to $\mathrm{CH}$ conduits. ${ }^{3} \mathrm{Can} \mathrm{CH}$ conduits be a sustainable solution, however, to limiting the devastating complication of IE? With a growing demand for pulmonary valve replacements and limited supply of homografts, let alone other degenerative tendencies of $\mathrm{CH}$ conduits, we may still need to resort to bovine pericardial valves and BJV conduits. The experimental studies of Ditkowski and colleagues ${ }^{1}$ with dual 
antiplatelet therapy may be the first step in providing a panacea for this dilemma, with the ultimate step being a well-designed clinical trial.

\section{References}

1. Ditkowski B, Bezulska-Ditkowska M, Jashari R, Baatsen P, Moreillon P, Rega F, et al. Antiplatelet therapy abrogates platelet-assisted Staphylococcus aureus infec- tivity of biological heart valve conduits. J Thorac Cardiovasc Surg. 2021;161 e457-72.

2. Alassas K, Mohty D, Clavel MA, Husain A, Hijji T, Aljoufan M, et al. Transcath eter versus surgical valve replacement for a failed pulmonary homograft in the Ross population. J Thorac Cardiovasc Surg. 2018;155:1434-44.

3. Van Dijck I, Budts W, Cools B, Eyskens B, Boshoff DE, Heying R, et al. Infective endocarditis of a transcatheter pulmonary valve in comparison with surgical implants. Heart. 2015;101:788-93.
See Article page e457.

\section{Commentary: Prescribe two antiplatelet drugs and receive fewer calls for Staphylococcus aureus-induced prosthetic endocarditis}

\author{
Frank A. Baciewicz, Jr, MD
}

Prosthetic conduit endocarditis, particularly with Staphylococcus aureus, is a lethal and increasingly frequent complication of implanted valves/conduits. ${ }^{1,2}$ Ditkowski and colleagues have presented intriguing laboratory work suggesting that daily aspirin and a second antiplatelet drug (ticagrelor) will eliminate a significant incidence of $S$ aureus prosthetic endocarditis in their article, "Antiplatelet therapy abrogates platelet-assisted Staphylococcus aureus infectivity of biological heart valve conduits," 3 in this issue of the Journal.

In an elaborate series using bovine pericardial patch, cryopreserved pulmonary homograft, and bovine jugular vein, the adhesion of $S$ aureus to these tissues in flow chambers with various perfusates, including plasma, serum, phosphate-buffered saline, and anticoagulated blood, was assessed. The authors studied the effect of fibrinogen (Fg), platelets, and antiplatelet agents on $S$ aureus tissue adhesion. Initially, Fg was shown to bind to graft tissue and $S$ aureus adhesion was directly related to the Fg levels.

From the Department of Cardiothoracic Surgery, Michael and Marian Ilitch Department of Surgery, Wayne State University School of Medicine, Detroit, Mich.

Disclosures: Author has nothing to disclose with regard to commercial support.

Received for publication Nov 2, 2019; revisions received Nov 2, 2019; accepted for publication Nov 4, 2019; available ahead of print Nov 27, 2019.

Address for reprints: Frank A. Baciewicz, Jr, MD, Harper Hospital, 3990 John R St, Detroit, MI 48201 (E-mail: fbaciewi@dmc.org).

J Thorac Cardiovasc Surg 2021;161:e476-7

$0022-5223 / \$ 36.00$

Copyright (c) 2019 by The American Association for Thoracic Surgery

https://doi.org/10.1016/j.jtcvs.2019.11.023

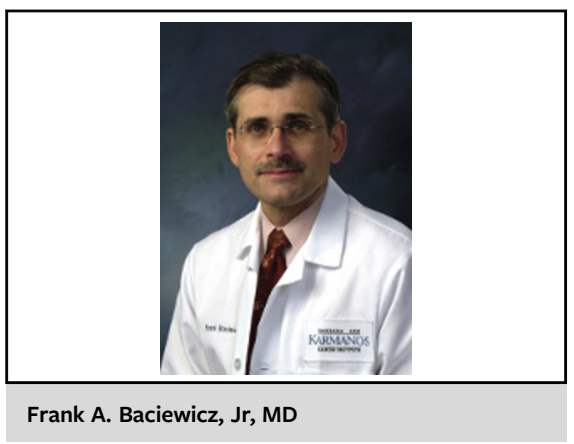

CENTRAL MESSAGE

Authors suggest taking two antiplatelet drugs (aspirin and ticagrelor) may be a remedy for $S$ aureus prosthetic valve/conduit infections. Is a clinical trial indicated?

Labeled S aureus and Fg were colocalized on the graft when microscopically examined.

The next step demonstrated platelet affinity for the graft material (bovine jugular wall and bovine patch had the greatest retention) both at the endothelial cell surface and the subendothelial tissue matrix. This was confirmed with scanning electron microscopy. Platelet adhesion was also directly related to $S$ aureus proclivity for graft tissue. Both the platelet and $S$ aureus adhesion were blocked by administering eptifibatide, an $\alpha_{\mathrm{IIb}} \beta_{3}$ platelet-binding site antagonist.

The experimental sequence of flow studies demonstrated $S$ aureus adhesion to Fg decreased without the presence of platelets and that $\mathrm{Fg}$ was necessary for platelet-induced $S$ aureus attachment to graft tissue. Making sense of the washing and coating of the grafts before perfusion, adding Fg to serum and other perfusates, the sequence of perfusion, 